\title{
Experimental infection of a periodical cicada (Magicicada cassinii) with a parasitoid (Emblemasoma auditrix) of a proto-periodical cicada (Okanagana rimosa)
}

\author{
Reinhard Lakes-Harlan ${ }^{*}$ and Thomas de Vries
}

\begin{abstract}
Background: The proto-periodical cicada Okanagana rimosa is subject to infection by the acoustically orientating parasitoid fly Emblemasoma auditrix. Furthermore, it is also the only known host of E. auditrix. Here we test the question, whether the highly adapted parasitoid can also infect other cicadas, like the periodical cicada (Magicicada cassinii) and which steps of the parasitization process can be completed. The experiments might also reveal whether such a parasitoid could hypothetically have been involved in the evolution of periodicity.

Results: The hearing threshold of E. auditrix matches with the spectrum of the calling song of $M$. cassinii, indicating potential host localization. Behaviourally, host localization is possible by the parasitoid as it approaches a loudspeaker broadcasting the buzz part of the calling song of $M$. cassinii. Magicicada cassinii is readily accepted as host and for host infection the parasitoid uses the same behavioural sequence as for its host O. rimosa. A larva is deposited into the timbal of the cicada. By contrast to $O$. rimosa the development of the fly larva is delayed and eventually suppressed in M. cassinii.

Conclusions: The host range of $E$. auditrix is mainly determined by acoustic parameters. This filter is important, as other sensory cues seem not to be involved in the host selection process and larva will not develop in unsuited host. Although the recent parasitoid-host system seems to be stable in terms of coexistence of both species, an acoustically hunting parasitoid could have been a selective force during evolution of prime numbered periodicity in cicadas.
\end{abstract}

Keywords: Host location, Host suitability, Evolution of periodicity, Auditory system

\section{Background}

Adults of the three different species of periodical cicadas, Magicicada cassinii (Fisher), M. septendecim (Linnaeus) and M. septendecula (Alexander \& Moore), appear every 17 years above ground [1]. Their nymphs live underground where they feed on roots before emerging as adults. The unarmed and harmless insects are attacked by parasitoids and predators, like birds and mammals, often until the predators are satiated [1]. The survival of these cicada populations is probably secured by their high abundance and by their unusual life cycle [1,2]. The

\footnotetext{
* Correspondence: Reinhard.Lakes-Harlan@physzool.bio.uni-giessen.de Integrative Sensory Physiology, Institute of Animal Physiology, Justus-Liebig-University Giessen, Heinrich-Buff Ring 26, D 35392 Giessen, Germany
}

evolutionary origin of this long periodic life cycle with synchronous emergence of three reproductively isolated species is subject to discussion for a long time [1,3]. Model calculations have shown that such a periodic life cycle with prime numbers can be a result of the selective pressure of parasites [4]. However, the model is based on hypothetical parasites. Therefore we experimentally tested whether the periodical cicada Magicicada cassinii could be a potential host of the geographically separated parasitoid fly Emblemasoma auditrix (Soper).

Females of the parasitoid fly Emblemasoma auditrix (Diptera, Sarcophagidae) acoustically locate their host, the male cicada Okanagana rimosa (Say) (Hemiptera, Cicadidae) [5,6] and distributions of both species overlap at least in the South of Ontario (Canada) and Michigan 
(USA). The auditory cue is the calling song of the male cicada intended to attract conspecific females [7]. Emblemasoma auditrix has evolved a tympanal organ at the prothorax to overhear that song and to localize the cicada [8]. When a fly finds a host, it approaches the host and rapidly deposits a fully developed larva into the timbal of the cicada [9]. The larva feeds inside the cicada and leaves it after about six days thereby killing the host [9]. Okanagana rimosa is so far the only known host of E. auditrix and it remains to be shown which parameter limits the host range of the parasitoid.

Therefore we tested with the experimental infection of periodical cicadas also the limits and effectiveness of the parasitization process. We performed experiments to analyse three steps of the parasitization process: host location, host acceptance and host suitability [10]. Although $M$. cassinii seems not to be a suitable host in our experiments, the initially successful parasitization process suggests that this recent parasitoid might serve as a factor in the model for the origin of periodicity and species separation in cicadas.

\section{Results}

The parasitoid E. auditrix uses the acoustic signal of the cicada $O$. rimosa as long range cue for host location. Therefore, we first correlated the hearing range to the frequency content of the calling songs of cicada species. The hearing range of the fly and the calling song spectrum of the periodical cicada $M$. cassinii match in the range of 4-7 kHz (Figure 1A). This overlap enables phonotaxis of $E$. auditrix to the calling song of $M$. cassinii and is even more pronounced than that in the recent parasitoid-host system (E. auditrix - O. rimosa). The hearing threshold does not match to the spectrum of $M$. septendecim.

Secondly, phonotaxis tests have been performed. In the field almost no fly could be attracted to the calling songs of $M$. cassinii or M. septendecim. However, flies did respond to song models of the buzz part of the calling song of $M$. cassinii (Figure 1B). Nevertheless, the number of attracted flies was lower than those to the song model of the host (Figure 1B). In behavioural tests in the laboratory almost all flies $(96 \% ; n=22)$ reacted with an initial turn towards the signals of both, $O$. rimosa and M. cassinii. The percentage of flies continuing and completing phonotactic approach depended on the signal (Figure 1B), with the calling song of O. rimosa being the more attractive signal. Nevertheless, $55 \%$ of flies completed phonotaxis towards the signal of $M$. cassinii (Figure 1B).

For experiments on the second step of parasitization, host acceptance, male $M$. cassinii were restrained to a loudspeaker and presented to acoustically attracted flies. Emblemasoma auditrix landed on or nearby the cicada, moved around the potential host, visually identified the

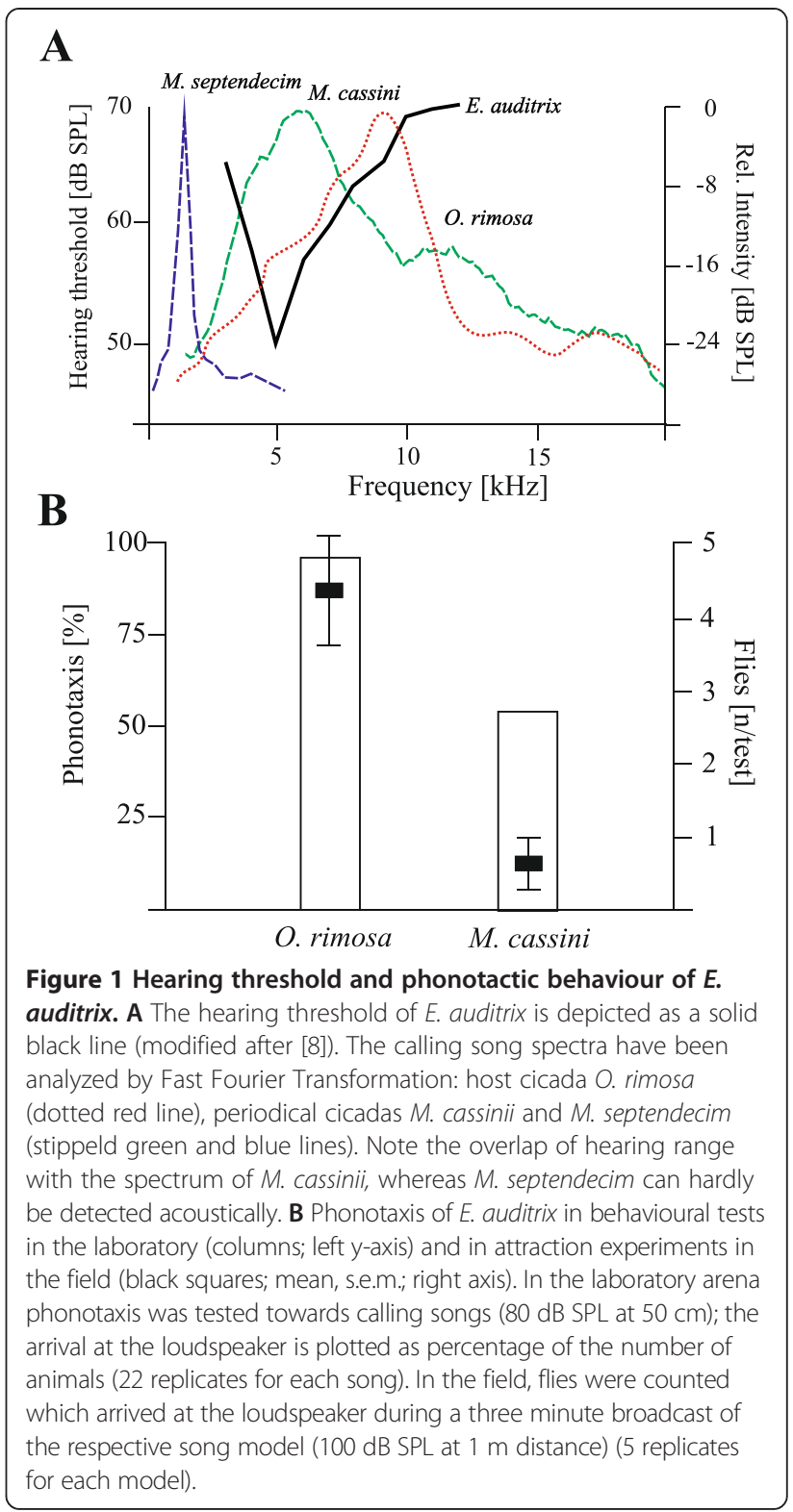

abdomen and approached the host from the caudal side. The parasitoid squeezed underneath the wings and deposited one larva into the timbal, the sound producing organ of the cicada. The timbal was usually injured posterior-ventrally at the timbal ribs $8-11$ (Figure 2A) and 2 to 3 ribs (mean 2.4; s.e.m. 0.12; $\mathrm{n}=40$ ) were broken. During experimental infection $M$. cassinii displayed defence behaviour, like flipping of wings (in $80 \%$ of the experiments; $\mathrm{n}=80$ ) and production of disturbance squawks (65\%). However, in 55\% of all experiments flies managed to stay on the cicada and proceed with infection behaviour.

The third step of the parasitization process, host suitability, was tested in the infection experiments in which a male cicada was presented to acoustically attracted $E$. 

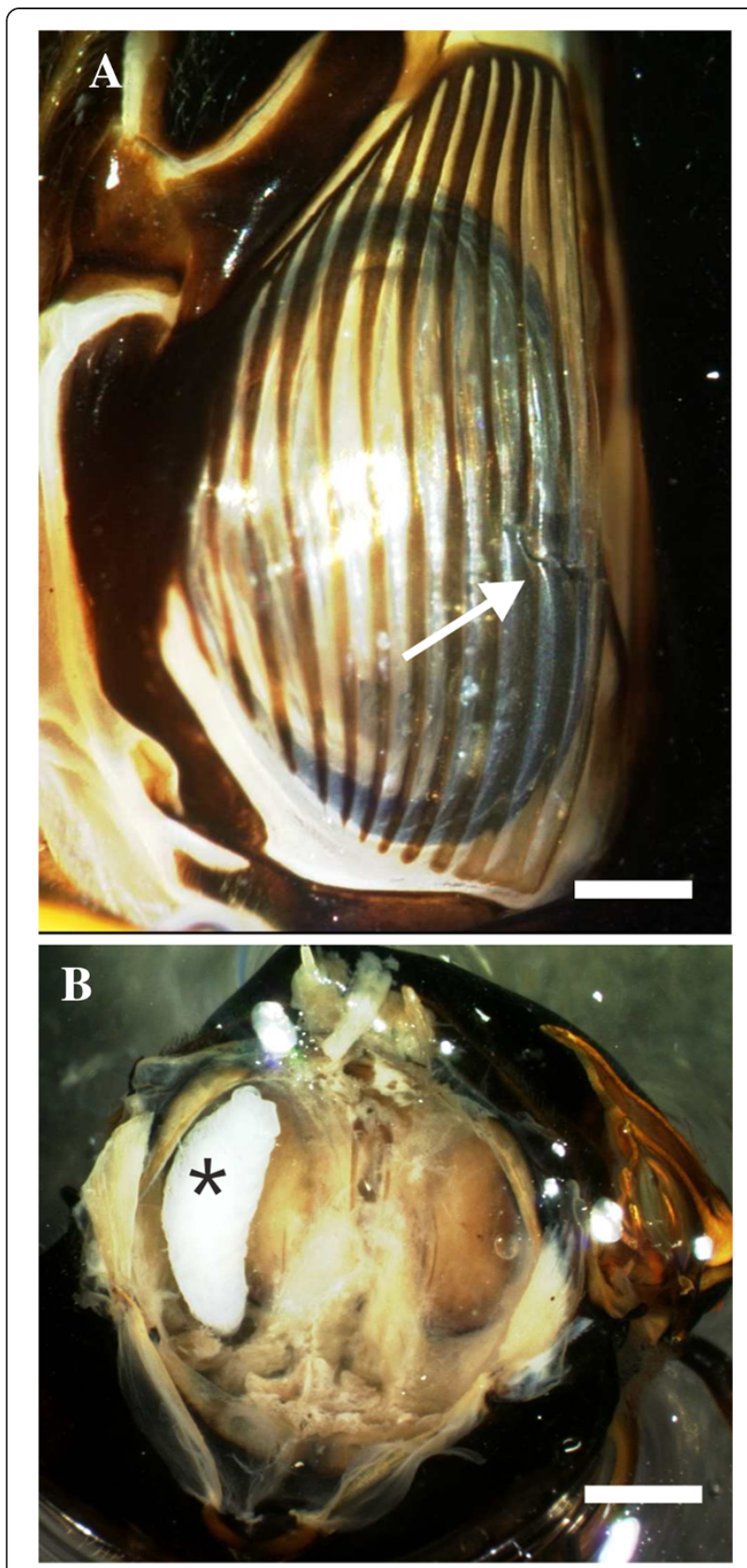

Figure 2 Photomicrographs of the injured timbal and the larva feeding inside the host cicada. A Timbal of $M$. cassinii with an injury at the ribs 8-11 (arrow). The ribs were broken during the injection of the parasitoid larva. B Second instar larva (asterisk) lying in the abdomen close to the timbal cavity of a host cicada. Scales: A: $500 \mu \mathrm{m} ; \mathrm{B}: 2 \mathrm{~mm}$.

auditrix $(\mathrm{n}=69)$. During infection a single larva was deposited in the timbal of $M$. cassinii. The larva proceeded into the abdomen of the host (Figure 2B). First instar larvae were found up to five days after infection and second instar larvae started to occur from the third day after infection (Table 1). After six days in captivity most of cicadas were dead, although the tissue damaging due to feeding by the larvae was low. In a surviving cicada, a still second instar larva was found 10 days after infection. In comparison, the fly larvae developed faster in the host cicada, O. rimosa (Table 1). Typically, the second stage was reached by day 3 and the third stage was reached by days 5 to 6 post infection. After 6 to 7 days post infection host cicadas were dead caused by the feeding of the fly larva.

These results show that $E$. auditrix is able to infect the non-host periodical cicada $M$. cassinii by using its unique acoustic host finding. However, the larvae do not develop completely in the host.

\section{Discussion}

Host range of $E$. auditrix and parasitization of $M$. cassinii

The data show that in an experimental situation $E$. auditrix is able to locate, accept and infect the periodical cicada $M$. cassinii. It is not known whether $E$. auditrix has a geographical overlap with $M$. cassinii. In the geographical range of $E$. auditrix in Northern Michigan mainly two other cicada species besides $O$. rimosa occur, but no phonotactical attraction to songs of $O$. canadensis (Provancher) or Tibicen canicularis (Harris) has been found in field experiments [6]. By contrast, other Emblemasoma species prefer calling songs from one species, but can be attracted to other songs as well [11]. Nevertheless in comparison to acoustically orientating Ormiini, species of Emblemasoma might have a narrower host range [12]. The host range might be determined by acoustic parameters of the host's calling songs.

The hearing range of the fly allows listening to the calling songs of a number of cicada species as their frequency spectra often peak between 5 and $10 \mathrm{kHz}$ [13]. The hearing threshold of E. auditrix matches well with the spectrum of the song from $M$. cassinii. The mismatch to the spectrum of the host O. rimosa is even more surprising and could not be explained so far [6]. Besides frequency content, the temporal structures of the sounds are important for recognition in insects [14]. The parasitoid is adapted to the signal/pulse ratio of the host $O$. rimosa and other patterns are less attractive [6]. Therefore it is not surprising, that the fly has not been attracted to songs of periodical cicadas. However, broadcasting of a song model with the pulse structure of the buzz part from the calling song of $M$. cassinii attracted flies, although the behavioural response was weaker than to the song of the host species.

While the acoustic cue might be a good filter for host selection, what about host infection and host suitability? The host infection behaviour involves a sequence of visual and tactile cues, and is highly specialized with injection of a larva into the timbal of the male cicada [9]. Emblemasoma auditrix can apply this whole behavioural sequence to $M$. cassinii although this cicada exhibits more defensive 
Table 1 Larval stage (LS) of E. auditrix in relation to the post infection time in the cicadas M. cassinii and 0 . rimosa

\begin{tabular}{|c|c|c|c|c|c|c|c|c|}
\hline \multirow{2}{*}{$\begin{array}{l}\text { Days post } \\
\text { infection }\end{array}$} & \multicolumn{4}{|l|}{ M. cassinii } & \multicolumn{4}{|l|}{ O. rimosa } \\
\hline & 1. LS (Percent) & 2. LS (Percent) & 3. LS (Percent) & (n) & 1. LS (Percent) & 2. LS (Percent) & 3. LS (Percent) & (n) \\
\hline 1 & 100 & 0 & 0 & 4 & 100 & 0 & 0 & 5 \\
\hline 2 & 100 & 0 & 0 & 6 & 90 & 10 & 0 & 10 \\
\hline 3 & 88 & 12 & 0 & 8 & 0 & 100 & 0 & 9 \\
\hline 4 & 50 & 50 & 0 & 8 & 8 & 58 & 33 & 12 \\
\hline 5 & 50 & 50 & 0 & 2 & 0 & 36 & 64 & 14 \\
\hline 6 & 0 & 100 & 0 & 3 & 9 & 0 & 91 & 11 \\
\hline 10 & 0 & 100 & 0 & 1 & - & - & - & - \\
\hline
\end{tabular}

A total of 69 M. cassinii and 108 of $O$. rimosa was infected and samples were analysed for larval development each day post infection. The larval stage is presented as percent of the individuals in the sample (columns " $n$ "). Note that although in $M$. cassinii no larva reached the third instar only a few cicadas survived more than six days. In O. rimosa the third larval instar of E. auditrix kills its host after 6 to 7 days.

behaviour than O. rimosa. Emblemasoma auditrix succeeds in an injection of a larva into the timbal, whereby timbal ribs at a similar location are broken as in $O$. rimosa [9]. Thus, host infection behaviour seems not to be decisive for host selection. However, $M$. cassinii seems to be less suited as host. In $M$. cassinii the larva showed a delayed development (up to five days for the first instar larva) and no larva reached the third stage. The larval development in $O$. rimosa is faster ( 6 days until emergence of the third instar larva from the host) and has higher survival rates (de Vries \& Lakes-Harlan unpublished results). Although the overall mortality of the M. cassinii might influence the parasitoid's larval development, the infection process indicates less suited internal conditions in the periodical cicada. Host selection and host suitability depend on numerous factors [15] and it remains to be shown, whether active defence mechanisms of the cicada or other conditions are responsible for suppressing parasitoid development. Cicada species that are more closely related to O. rimosa might be more suited as an (experimental) host for $E$. auditrix.

In summary, a selective response of $E$. auditrix to the acoustic parameters seems to be important, because host infection is unselective and larvae die in non-suited hosts.

\section{Hypothetical impact of a parasitoid on evolution of periodicity}

M. cassinii has also been chosen here as an experimental species in respect to the question of evolution of periodicity in cicadas. Models have shown that due to interaction of multiple factors, populations can become periodic or generate outbreaks with huge numbers of individuals $[4,16]$, like the periodical cicadas. One of these factors could be a parasitoid, like E. auditrix, which is in the described experimental situation able to infect the periodical cicada $M$. cassinii. Such a scenario is hypothetical but might not be too farfetched, as some lines of arguments can support it. 1) An acoustically hunting parasitoid might explain the low frequency peak of $M$. septendecim. In cicadas a correlation between body length and carrier frequency has been found [17]. Magicicada cassinii and $M$. septendecula have carrier frequencies corresponding to their body length. The species $M$. septendecim has a much lower frequency, which is mechanically a result of a reduction of the stiffness of the timbal [18]. The large difference between the peak frequencies of $M$. cassinii and M. septendecim does not seem to be necessary for pairformation, because in 13-year periodical cicadas a difference of $300 \mathrm{~Hz}$ is sufficient for species separation [19]. Speculatively, both the lower frequency and the reduced stiffness might be a result of natural selection pressure by a parasitoid like E. auditrix. In another system with an acoustically hunting tachinid parasitoid and a calling bushcricket, a low carrier frequency in the calling song has also been attributed to the parasitoid pressure [20]. The reduced stiffness or increased flexibility of the timbal might be advantageous for avoiding parasitization, as in O. rimosa [9] as well as in M. cassinii usually one or more of the stiff timbal ribs were broken during infection. Soft tissue might be less suited for larvae injection and infection experiments with $M$. septendecim should verify this hypothesis. Thus, both factors might contribute to avoidance of acoustically hunting parasitoids in this species. 2) Infection rates of $O$. rimosa can reach more than $80 \%$ in local populations (see below). Together with pathogenic fungi [21,22] and limited environmental carrying capacities [23] these factors might contribute for the evolution of strong periodicity. 3) A hypothetical switch of host species might explain the mismatch of the hearing threshold and the frequency spectrum in the recent host-parasitoid system. In other Emblemasoma a match of both, threshold and spectrum, has been reported [11].

Assuming an acoustically hunting parasitoid in the evolution of periodical cicadas, it might have been involved in two different phases. The evolution of the periodical life cycle in the genus Magicicada must have preceded species 
formation [24]. If an acoustically hunting parasitoid was involved in the evolution of periodicity, the selection pressure must have persisted until species formation of $M$. septendecim with its low frequency calling song. Thereafter the parasitoid might have become extinct or, perhaps, even acquired a new host species, like O. rimosa. An indication might be the geographic distribution, whereby $M$. septendecim and $O$. rimosa are predominantly found in the Northeast of the US [3], even though today their distribution overlaps only partially.

\section{Balance in the recent host-parasitoid system}

Assuming that E. auditrix or an extinct relative could have been a decisive factor for evolution of periodical cicadas and changes in the calling song structure, what effect does the parasitoid impose on the recent host $O$. rimosa? An analysis of the host-parasitoid interactions reveals specific adaptations indicating a long evolutionary trait between both species. The parasitoid has specific sensory and behavioural adaptations (see also above), like the tuning to the temporal and spectral parameters of the calling song [25], the specialized infection behaviour with partial destruction of the sound producing organ [9] and the low number of larvae per parasitoid [26]. The specific adaptations of the host are less obvious. Due to the seemingly very limited external and internal defence capabilities of O. rimosa [9], avoidance of parasitization could be a line of defence. This avoidance involves changes in the calling song (as suggested for M. septendecim) or changes in the life cycle. Until now no population of $O$. rimosa without parasitoids is known and therefore the effect of the parasitization on the calling song could not be studied yet. An adaptation of the host might be that their populations show large fluctuations in densities, which have been called proto-periodic [1]. However, despite the probable 8-9 year life-cycle [1], adults of $O$. rimosa emerge in each year. Very low numbers in some years might contribute to local breakdowns of parasitoid populations (unpublished data), which, however, might reinvade habitats in years with higher host abundance. On the other hand, a less synchronized emergence of $O$. rimosa (in comparison to the periodical cicadas) and a corresponding slow increase in singing probability might deplete the parasitoid of its larvae and ensure reproduction of the cicada. By the time singing activity peaks, only a few larvae are present in a fly [26] because most larvae are injected into cicadas directly after singing started. This temporal sequence also indicates the high effectiveness of host localisation for an acoustically hunting parasitoid.

\section{Conclusion}

The host range of E. auditrix is mainly determined by acoustic parameters. This filter is important, as other sensory cues seem not to be involved in the host selection process and larva will not develop in an unsuited host. Although the recent parasitoid-host system seems to be stable in terms of coexistence of both species, an acoustically hunting parasitoid could have been a selective force during evolution of prime numbered periodicity in cicadas. In our hypothetical scenario combined selective forces might have led to the evolution of proto-periodicity and periodicity. The hypothesis could also explain why only a few species of cicadas became strictly periodic: the sensory mechanism of acoustic host location is rather unique by itself.

\section{Methods}

Recordings of calling songs took place at several locations in Defiance County, Ohio (Magicicada cassinii) and in the County of Cincinnati, Ohio (M. septendecim). The calling songs were recorded on a DAT recorder (Sony 5 DJA; $44.1 \mathrm{kHz}$ sampling rate) using a Bruel \& Kjaer 2203 sound level meter with calibrated microphone. 25 recordings were made from $M$. cassinii and 10 recordings from $M$. septendecim at different locations and in different distances to the calling males. The recordings were compared to those deposited on a webpage of the University of Michigan (http://insects.ummz. lsa.umich.edu/fauna/Michigan_Cicadas/Periodical/Index. html). No differences were found between our recordings and therefore the song models (see below) have been designed according to the temporal structures of calling songs from the webpage. Three songs from single individuals of each species were analyzed by Fast Fourier Transformation Analysis (Hewlett-Packard 5327; 2048 lines; Hanning filter; $44.1 \mathrm{kHz}$ sampling rate).

Magicicada cassinii was collected in Defiance County, Ohio (41.184767, -84.311673); the parasitoid fly Emblemasoma auditrix and the cicada O. rimosa were collected in Emmet County, MI (45.582601, -84.743735). For collection, female flies were attracted to a loudspeaker broadcasting the calling song of the host $O$. rimosa (for details see [6]). Therefore all tested flies were phonotactically active, although their individual age was unknown. The cicadas were kept in screened tents places above some bushes in the field.

Phonotaxis tests in the field (Emmet County, MI) were performed with recorded calling songs of O. rimosa, $M$. cassinii and $M$. septendecim as well as song models for tests with higher sound pressure levels. The song model of $O$. rimosa had a carrier frequency of $9 \mathrm{kHz}$ and a temporal structure with $6 \mathrm{~ms}$ pulse duration followed by $6 \mathrm{~ms}$ pause; for the song model of $M$. cassinii the buzz part of the calling song [2] was selected due to its temporal structure. The song model had a carrier frequency of $6 \mathrm{kHz}$ and a temporal structure with $3 \mathrm{~ms}$ pulse duration followed by a $1 \mathrm{~ms}$ pause. Song models from other parts of calling songs form periodical cicadas were not 
attractive (data not shown). The signals were generated using the CoolEdit software, stored on a compact disc and broadcasted for three minutes each. The sound intensity was adjusted to values between 98 and $100 \mathrm{~dB}$ SPL (relative to $\mathrm{P}_{0}=2 \times 10^{-5} \mathrm{~N} \mathrm{~m}^{-2}$ ) at $1 \mathrm{~m}$ using a sound level meter (Bruel \& Kjaer 2203).

The behavioural tests took place in the laboratory at the University of Michigan Biological Station. Therefore flies were kept in small cages with sugar and water ad libitum. A fly which had its wings clipped off $(\mathrm{n}=22)$ was released at a starting point in $50 \mathrm{~cm}$ distance to a hidden loudspeaker placed in one wall of the test arena (for details see [25]. The signals (as described above) were broadcasted with $80 \mathrm{~dB}$ SPL measured at the starting point. The walking behaviour and phonotaxis of the fly was videotaped.

To test host infection, a male $M$. cassinii was attached on top of a loudspeaker broadcasting the calling song of $O$. rimosa to attract flies in the field. After phonotaxis of a fly the sound was turned off and the parasitoid could interact with the potential host. After the fly left the cicada, the latter was analysed for injuries due to the infection. For host suitability experiments, male $M$. cassinii were presented to the parasitoid by holding it at the head on top of the loudspeaker. Such presentation allows infection behaviour by the parasitoid. Infected cicadas $(n=69)$ were kept in a screened tent placed above some bushes in the field. Samples of infected cicadas were dissected daily and analysed for presence and stage of larvae. After six days in captivity most cicadas were dead; this rate of mortality was the same for infected and non-infected cicadas. Additionally, 108 host cicadas (O. rimosa) were infected and kept under the same conditions as $M$. cassinii above. Photos were taken on a stereo microscope equipped with a CCD camera.

\section{Competing interests}

The authors declare that they have no competing interests.

\section{Authors' contributions}

$\mathrm{RLH}$ designed the study and drafted the manuscript. TdV carried out the experiments and participated in the manuscript drafting. Both authors analysed the data. Both authors read and approved to final manuscript.

\section{Acknowledgements}

We thank Drs K. Reinhold, T. Moore and A. Stumpner for discussion on an earlier version of the manuscript. We thank the Biological Station of the University of Michigan (UMBS) for a stimulating environment. The study was supported by an UMBS grant to Th. deVries.

Received: 21 July 2014 Accepted: 5 December 2014

Published online: 14 December 2014

\section{References}

1. Williams KS, Simon C: The ecology, behavior, and evolution of periodical cicadas. Annu Rev Entomol 1995, 40:269-295.

2. Alexander RD, Moore TE: Studies on the acoustical behavior of seventeen-year cicadas (Homoptera: Cicadidae: Magicicada). Ohio J Sci 1958, 58:107-127.

3. Lloyd M, Dybas H: The periodical cicada problem. II. Evolution. Evolution 1966, 20:466-505.
4. Goles E, Schulz O, Markus M: Prime number selection of cycles in a predator-prey model. Complexity 2001, 6:33-38.

5. Soper RS, Shewell GE, Tyrrell D: Colcondamyia auditrix nov. sp. (Diptera: Sarcophagidae), a parasite which is attracted by the mating song of its host, Okanagana rimosa (Homoptera: Cicadidae). Can Entomol 1976, 108:61-68.

6. Lakes-Harlan R, Stölting H, Moore TE: Phonotactic behavior of a parasitoid (Emblemasoma auditrix, Sarcophagidae, Diptera) in response to the calling song of the host (Okanagana rimosa, Homoptera, Cicada). Zoology 2000, 103:31-39.

7. Stölting H, Moore TA, Lakes-Harlan R: Acoustic communication of Okanagana rimosa (Say)(Homoptera: Cicadidae). Zoology 2004, 107:243-257.

8. Lakes-Harlan R, Stölting H, Stumpner A: Convergent evolution of insect hearing organs from a preadaptive structure. Proc R Soc B 1999, 266:1161-1167.

9. Schniederkötter K, Lakes-Harlan R: Infection behavior of a parasitoid fly, Emblemasoma auditrix and its host cicada Okanagana rimosa. J Insur Sci 2004, 4:36-37.

10. Godfray H: Parasitoids: Behavioral and Evolutionary Ecology. Princeton, New Jersey: Princeton University Press; 1994.

11. Farris HE, Oshinsky ML, Forrest TG, Hoy R: Auditory sensitivity of an acoustic parasitoid (Emblemasoma sp., Sarcophagidae, Diptera) and the calling behavior of potential hosts. Brain Behav Evol 2008, 72:16-26.

12. Lehmann GUC: Review of biogeography, host range and evolution of acoustic hunting in Ormiini (Insects, Diptera, Tachinidae), parasitoids of night-calling bushcrickets and crickets (Insecta, Orthoptera, Ensifera). Zool Anz 2003, 242:107-120.

13. Popov AV: Co-Evolution of Sound-Production and Hearing in Insects. In Sensory Systems and Communication in Arthropods. Edited by Gribakin FG, Wiese K, Popov AV. Basel, Boston, Berlin: Birkhäuser Verlag; 1990:301-304.

14. Pollack GS: Who, what, where? Recognition and localization of acoustic signals by insects. Curr Opin Neurobiol 2000, 10:763-767.

15. Vinson SB: Host selection by insect parasitoids. Annu Rev Entomol 1976, 21:109-133.

16. Dwyer G, Dushoff J, Yee SH: The combined effects of pathogens and predators on insect outbreaks. Nature 2004, 430:341-345.

17. Bennet-Clark HC, Young D: The scaling of song frequency in cicadas. J Exp Biol 1994, 191:291-294.

18. Young $D$, Josephson RK: Pure-tone songs in cicadas with special reference to the genus Magicicada. J Comp Physiol 1983, 152:197-207.

19. Marshall DC, Cooley JR: Reproductive character displacement and speciation in periodical cicadas, with description of a new species, 13-year Magicicada neotredecim. Evolution 2000, 54:1313-1325

20. Römer H, Bailey W: Strategies for hearing in noise: peripheral control over auditory sensitivity in the bushcricket Sciarasaga quadrata (Austrosaginae: Tettigoniidae). J Exp Biol 1998, 201:1023-1033.

21. White J, Lloyd M: A pathogenic fungus, Massospora cicadina Peck (Entomophthorales), in emerging nymphs of periodical cicadas (Homoptera: Cicadidae). Environ Entomol 1983, 12:1245-1252.

22. Soper RS: The genus Massospora, entomopathogenic for cicadas, part I, taxonomy of the genus. Mycotaxon 1974, 1:13-40.

23. Hoppensteadt F, Keller J: Synchronization of periodical cicada emergences. Science 1976, 194:335-337.

24. Cooley J, Simon C, Marshal D: Temporal separation and speciation in periodical cicadas. Bioscience 2003, 53:151-157.

25. Köhler U, Lakes-Harlan R: Auditory behaviour of a parasitoid fly (Emblemasoma auditrix, Sarcophagidae, Diptera). J Comp Physiol A 2001, 187:581-587.

26. deVries T, Lakes-Harlan R: Phonotaxis of the female parasitoid Emblemasoma auditrix (Diptera, Sarcophagidae) in relation to number of larvae and age. Zoology 2005, 108:239-246.

doi:10.1186/s12898-014-0031-7

Cite this article as: Lakes-Harlan and de Vries: Experimental infection of a periodical cicada (Magicicada cassinii) with a parasitoid (Emblemasoma auditrix) of a proto-periodical cicada (Okanagana rimosa). BMC Ecology 2014 14:31. 